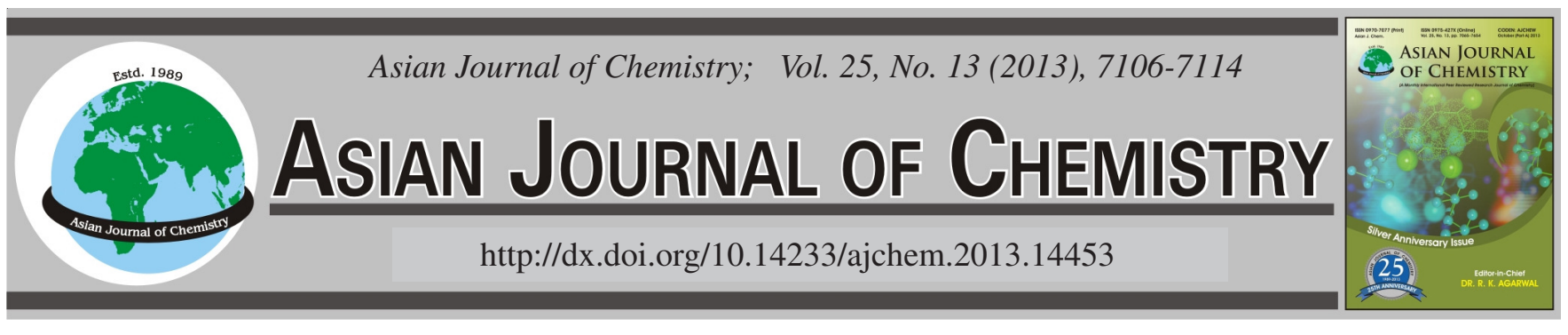

\title{
Infrared Spectra, Density Functional Theory and Hartree-Fock Theoretical Calculations of 2-Methyl-8-quinolinol
}

\author{
K. ARICI ${ }^{1, *}$ and R. YILMAZ ${ }^{2}$
}

${ }^{1}$ Department of Physics, Faculty of Science and Arts, Kilis 7 Aralik University, 79100 Kilis, Turkey ${ }^{2}$ Department of Physics, Faculty of Science and Arts, Yüzüncü Yil University, 65100 Van, Turkey

*Corresponding author: Fax: +90 348 8222351; Tel: +90 348 8202350; E-mail: arici@kilis.edu.tr

(Received: 17 August 2012;

Accepted: 14 June 2013)

AJC-13652

\begin{abstract}
The Fourier transform infrared and Raman spectra of 2-methyl-8-quinolinol have been recorded at solid phase and in the region 4000-400 $\mathrm{cm}^{-1}$. The molecular geometry, vibrational frequency, infrared intensities bands of 2-methyl-8-quinolinol in ground state have been calculated by Hartree-Fock and density functional theory with the B3LYP, BLYP and B3PW91 functional and 6-311G(dp) basis set, respectively. The calculated frequencies has been scaled which compared with experimental infrared and Raman spectra. The geometry and normal modes of vibration obtained from the Hartree-Fock and density functional theory methods are in good agreement with the experimental data.
\end{abstract}

Key Words: 2-Methyl-8-quinolinol, FTIR, FT-Raman Hartree-Fock, Density functional theory.

ᄂ - - - - - - - - - - - - - - - - - - - - - - - - - - - -

\section{INTRODUCTION}

Quinoline and its substituted derivatives are well known for antifungal, antibacterial, antiamoebic and antimicrobial activities ${ }^{1,2}$. These molecules are widely employed as good fluorogenic ligand binding with many metal cations due to its low quantum yield in aqueous and in some organic solutions. Quinolines have been extensively used for the extraction and analytical determination of metal ions ${ }^{3,4}$. Important applications of quinoline and derivatives are use as antimalarial drugs, in manufacturing dyes, as food colorant and a $\mathrm{pH}$ indicator ${ }^{5,6}$.

X-Ray crystallographic structure of 2-methyl-8-hydroxy quinoline $^{7}$ and infrared spectra of hydroxyquinoline was determined ${ }^{8}$. Hydroxquinoline and its mercury(II) complexes ${ }^{9}$, DFT calculations of isoquinoline and 8-hydroxyquinoline ${ }^{10}$, infrared spectra and DFT of 8-hydroxyquinoline and its halogen derivatives ${ }^{11}$, fundamental vibrational of 6-hydroxyquinoline $\mathrm{e}^{12}, a b$ initio and DFT theoretical calculations ${ }^{13}$ were studied. Infrared absorption spectra 2-methyl-8-quinolinol were also observed ${ }^{14}$. Ab initio calculations on 2-, 3- and 4substituted quinoline are carried out in a search for a relationship between the molecular properties of these compounds ${ }^{15}$. $A b$ initio, density functional theory and structural studies were performed on 4-amino-2-methylquinoline ${ }^{16}$. Infrared and Raman spectra of the 2,4-diaminoquinazoline and 4-amino2-methylquinoline were studied by density functional theory ${ }^{17}$.
Although 2-methyl-8-quinolinol has been studied by IR spectroscopy, but band assignments are not available in literature. Here, we studied 2-methyl-8-quinolinol from the vibrational point of view. The HF and DFT(B3LYP, BLYP and B3PW91) theoretical calculations were calculated with the $6-311 \mathrm{G}(\mathrm{dp})$ basis set. This aim of the study is to make reasonably reliable first assignments of absorbance bands.

\section{EXPERIMENTAL}

The compound 2-methyl-8-quinolinol was purchased from the Sigma-Aldrich Chemical company. The infrared spectrum of 2-methyl-8-quinolinol has been recorded in the region 4000-400 cm $\mathrm{cm}^{-1}$, Bruker FTIR IFS 66/S spectrophotometer using $\mathrm{KBr}$ pellet technique and the FT-Raman spectrum of the sample was recorded between $3500-80 \mathrm{~cm}^{-1}$ regions on FRA-106/S spectrometer at METU, Ankara/Turkey. The observed infrared and Raman spectra of 2-methyl-8-quinolinol are shown in Fig. 1.

Computational details: The molecular structure of 2-methyl-8-quinolinol in the ground state (in vacuo) are optimized by HF and DFT(B3LYP, BLYP and B3PW91) with the 6-311G(dp) basis set. The optimized structural parameters were used in the vibrational frequency calculations at HF and DFT levels.

DFT for all studies reported in this paper has the following from

$E_{x c}=\left(1-a_{0}\right) E_{x}^{L S D A}+a_{0} E_{x}^{H F}+a_{x} \Delta E_{x}{ }^{B 88}+a_{c} E_{c}{ }^{L Y P}+\left(1-a_{c}\right) E_{c}{ }^{V W N}$ 


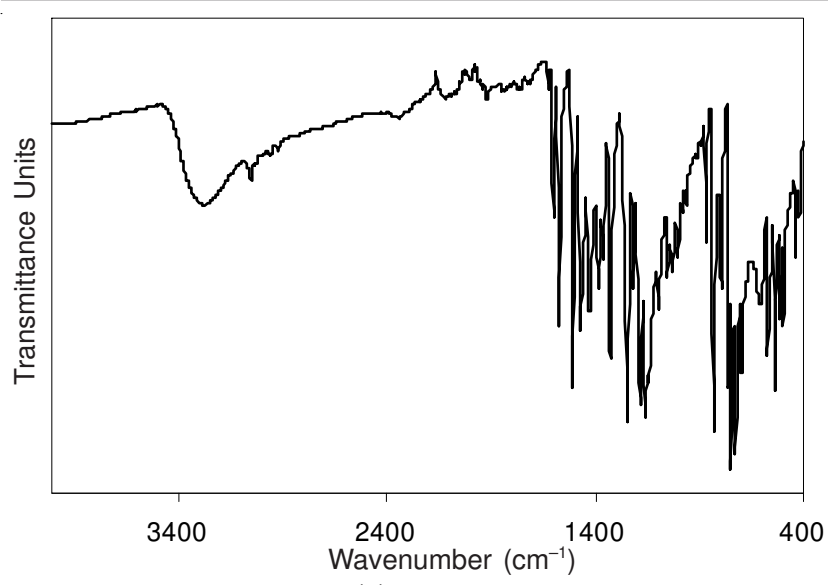

(a)

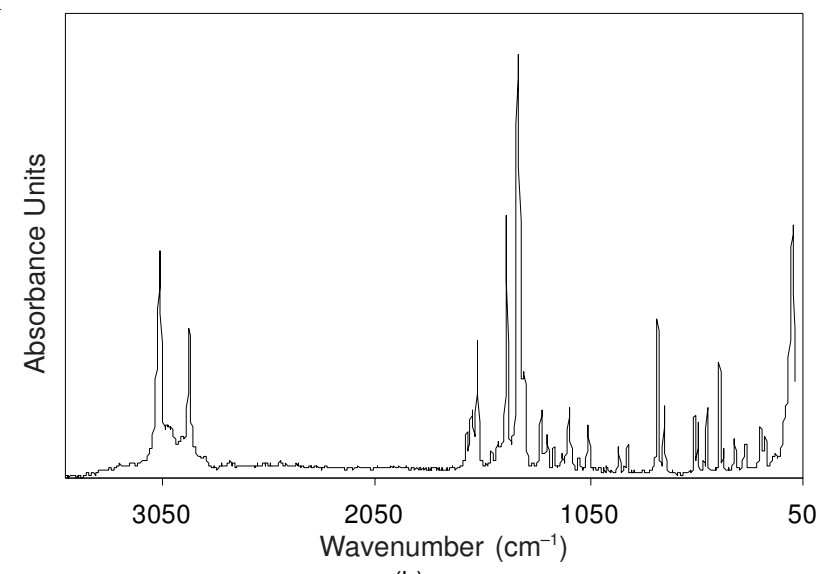

(b)

Fig. 1. (a) IR spectra and (b) Raman spectra of 2-methyl-8-quinolinol

where, the energy terms are the Slater exchange, the HartreeFock exchange, Becke's exchange functional correlation, the gradient correlated correlation functional of Lee, Yang and Parr and the local correlation functional of Vosko, Wilk and Nusair $^{18}$. HF/6-311G(dp), B3LYP/6-311G(dp), BLYP/6$311 \mathrm{G}(\mathrm{dp})$ and B3PW91/6-311G(dp) levels of theory with the optimized geometries have been used to calculate all parameters of the 2-methyl-8-quinolinol.

All the calculated vibrational frequencies are scaled by 0,9085 for HF/6-311G(dp), 0,9669 for B3LYP/6-311G(dp), 0,9962 for BLYP/6-311G(dp) and 0,9631 for B3PW91/6$311 \mathrm{G}(\mathrm{dp})^{19}$. Molecular geometry is not restricted and all the calculations are performed by using Gauss View molecular visualization program ${ }^{20}$ and GAUSSIAN09 program package on the personal computer ${ }^{21}$.

\section{RESULTS AND DISCUSSION}

The molecule of 2-methyl-8-quinolinol consist of 21 atoms, so it has 57 normal vibrational modes. The geometry of the molecule under investigation is considered by possessing $\mathrm{C}_{\mathrm{s}}$ point group symmetry. In this case, $\mathrm{OH}$ and $-\mathrm{CH}_{3}$ molecules groups as point masses are present within the molecular plane. Fifty seven fundamental modes of vibrations of the compound are distributed into the irreducible representations under $\mathrm{C}_{\mathrm{s}}$ symmetry as 38 in-plane vibrations of a' species and 19 out of plane vibrations of a" species, i.e., $\Gamma_{\text {vib }}=19 \mathrm{a} "+38 \mathrm{a}$ '. All vibrations are active in both IR and Raman spectra. All the frequencies are assigned in terms of fundamental, overtone and combination bands.

The molecular structure and numbering of the atoms of 2-methyl-8-quinolinol 1 is shown in Fig. 2.

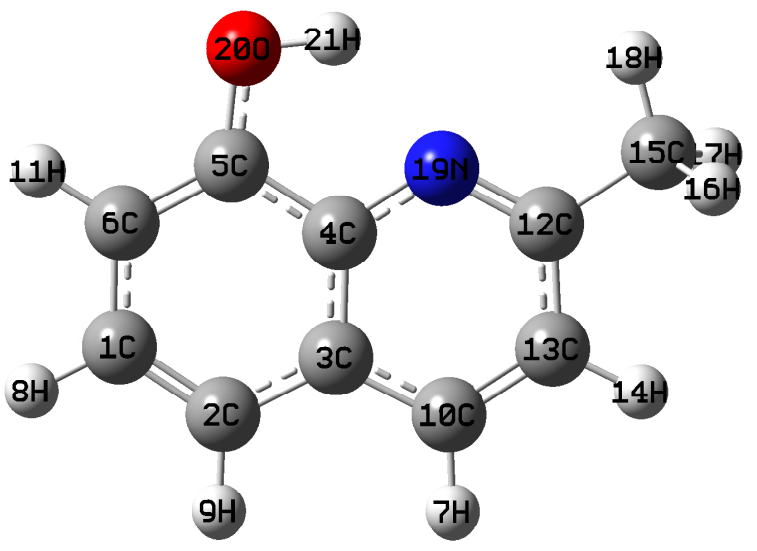

Fig. 2. 2-Methyl-8-quinolinol structure and atoms numbering

Geometrical structure: The optimized bond lengths and angles for 2-methyl-8-quinolinol at $\mathrm{HF}\left(6-311 \mathrm{G}^{* *}\right)$, DFT/ B3LYP(6-311G**), DFT/BLYP(6-311G**) and DFT/ B3PW91(6-311G**) levels are represented in Table-1 along with available experimental crystal data ${ }^{7}$.

As discussed in previous papers ${ }^{9-13}$ and their work $^{11,22,23}$, it is well known that HF methods underestimate for bond lengths. BLYP methods predict bond lengths which are systematically long, particularly C-H bond lengths. Since large deviation from experimental $\mathrm{C}-\mathrm{H}$ bond lengths may arise from the low scattering factors of hydrogen atoms in the $\mathrm{X}$-ray diffractions experiment so we did not discuss $\mathrm{C}-\mathrm{H}$ bond lengths.

From the structural data given in Table-1 it is observed that the influence of the substituent on the molecular structure, particularly in $\mathrm{C}-\mathrm{C}$ bond distance of ring carbon atoms seems to negligibly small except that $\mathrm{C} 4-\mathrm{C} 5$ and $\mathrm{C} 12-\mathrm{C} 13$ bonds lengths are longer than others quinoline rings, where the hydroxyl and methyl groups depends on C5 and C12 atoms, respectively. X-ray data of these bonds lengths are 1.417 and $1.415 \AA$, respectively ${ }^{7}$. The C4-C5 bond distance have been calculated at the $6-311 \mathrm{G}^{* *}$ level to be $1.422(\mathrm{HF})$, 1.418(B3LYP), 1.427(BLYP) and 1.425(B3PW91). This bond length was calculated as $1,433(\mathrm{~B} 3 \mathrm{LYP})^{10}, 1.425(\mathrm{HF})$, $1.430(\mathrm{~B} 3 \mathrm{LYP})$ and $1.440(\mathrm{BLYP})^{9}$ with $6-31 \mathrm{G}^{*}$ level for 8-hydroxyquinoline. The $\mathrm{C} 12-\mathrm{C} 13$ bond length have been calculated as 1.427(HF), 1.412(B3LYP), 1.423(BLYP) and 1.421(B3PW91) with 6-31G** level. The C12-C13 bond length was calculated as $1.42(\mathrm{HF}, \mathrm{B} 3 \mathrm{LYP})$ with $6-31 \mathrm{G}^{* *}$ and 6-311++D**levels for 4-amino-2-methylquinoline ${ }^{16}$. The C10$\mathrm{C} 13$ and N19-C12 bond distances are shorter than other C-C and $\mathrm{C}-\mathrm{N}$ bond lengths. These C10-C13 and N19-C12 bond distances are 1.352 and $1.319 \AA$, respectively. The N19-C12 bond distance was calculated as $1.32(\mathrm{~B} 3 \mathrm{LYP})$ with $6-31 \mathrm{G}^{* *}$ level and 1.29(HF) with 6-311++G** level for 4-amino-2-methylquinoline $^{16}, 1.293(\mathrm{HF}), 1.320(\mathrm{~B} 3 \mathrm{LYP})$ and 1.318(B3PW91) with 6-31G* level for 5,7-dichloro-8-hydroxyquinaldine ${ }^{13}$. All other in the quinoline ring $\mathrm{C}-\mathrm{C}$ bond distances are calculated in the range $1.352-1.427 \AA$. 
TABLE-1

GEOMETRIC PARAMETERS BOND LENGTHS ( $\mathrm{A})$ AND BOND ANGLES $\left({ }^{\circ}\right)$ OPTIMIZED FOR 2-METHYL-8-QUINOLINOL

\begin{tabular}{|c|c|c|c|c|c|c|}
\hline & $\begin{array}{c}\text { Bond lengths } \\
(\AA)\end{array}$ & $\begin{array}{c}\mathrm{HF} \\
6-311 \mathrm{G}(\mathrm{dp}) \\
\end{array}$ & $\begin{array}{c}\text { DFT/B3LYP 6- } \\
\text { 311G(dp) }\end{array}$ & $\begin{array}{c}\text { DFT/BLYP 6- } \\
311 \mathrm{G}(\mathrm{dp})\end{array}$ & $\begin{array}{c}\text { DFT/B3PW91 6- } \\
\text { 311G(dp) }\end{array}$ & $\begin{array}{l}\text { X-Ray } \\
\text { Ref. }\end{array}$ \\
\hline $\mathrm{R} 1$ & $\mathrm{C} 1-\mathrm{C} 2$ & 1.359 & 1.374 & 1.375 & 1.375 & 1.361 \\
\hline $\mathrm{R} 2$ & C1-C6 & 1.411 & 1.402 & 1.411 & 1.409 & 1.397 \\
\hline R3 & $\mathrm{C} 1-\mathrm{H} 8$ & 1.075 & 1.093 & 1.083 & 1.085 & 0.930 \\
\hline $\mathrm{R} 4$ & $\mathrm{C} 2-\mathrm{C} 3$ & 1.415 & 1.405 & 1.416 & 1.413 & 1.412 \\
\hline R5 & $\mathrm{C} 2-\mathrm{H} 9$ & 1.075 & 1.093 & 1.083 & 1.084 & 0.930 \\
\hline R6 & $\mathrm{C} 3-\mathrm{C} 4$ & 1.397 & 1.411 & 1.419 & 1.416 & 1.409 \\
\hline R7 & C3-C10 & 1.420 & 1.406 & 1.418 & 1.415 & 1.413 \\
\hline $\mathrm{R} 8$ & C4-C5 & 1.422 & 1.418 & 1.427 & 1.425 & 1.417 \\
\hline R9 & C4-N19 & 1.357 & 1.345 & 1.360 & 1.356 & 1.367 \\
\hline R10 & C5-C6 & 1.361 & 1.375 & 1.377 & 1.377 & 1.364 \\
\hline R11 & $\mathrm{C} 5-\mathrm{O} 20$ & 1.337 & 1.327 & 1.348 & 1.342 & 1.355 \\
\hline $\mathrm{R} 12$ & C6-H11 & 1.074 & 1.092 & 1.082 & 1.083 & 0.930 \\
\hline R13 & $\mathrm{C} 10-\mathrm{H} 7$ & 1.076 & 1.095 & 1.084 & 1.086 & 0.930 \\
\hline R14 & $\mathrm{C} 10-\mathrm{C} 13$ & 1.352 & 1.368 & 1.369 & 1.369 & 1.352 \\
\hline R15 & $\mathrm{C} 12-\mathrm{C} 13$ & 1.427 & 1.412 & 1.423 & 1.421 & 1.415 \\
\hline R16 & C12-C15 & 1.505 & 1.482 & 1.506 & 1.500 & 1.494 \\
\hline R17 & C12-N19 & 1.290 & 1.316 & 1.316 & 1.316 & 1.319 \\
\hline R18 & C13-H14 & 1.074 & 1.093 & 1.083 & 1.085 & 0.930 \\
\hline R19 & C15-H16 & 1.086 & 1.102 & 1.093 & 1.094 & 0.960 \\
\hline R20 & C15-H17 & 1.086 & 1.102 & 1.093 & 1.094 & 0.960 \\
\hline $\mathrm{R} 21$ & C15-H18 & 1.080 & 1.097 & 1.088 & 1.089 & 0.960 \\
\hline R22 & $\mathrm{O} 20-\mathrm{H} 21$ & 0.946 & 1.001 & 0.972 & 0.975 & 0.860 \\
\hline \multicolumn{7}{|c|}{ Bond angle $\left({ }^{\circ}\right)$} \\
\hline $\mathrm{A} 1$ & $\mathrm{C} 2-\mathrm{C} 1-\mathrm{C} 6$ & 121.37 & 122.28 & 121.69 & 121.85 & 121.40 \\
\hline $\mathrm{A} 2$ & $\mathrm{C} 2-\mathrm{C} 1-\mathrm{H} 8$ & 119.96 & 119.37 & 119.73 & 119.64 & 119.30 \\
\hline A3 & C6-C1-H8 & 118.65 & 118.34 & 118.56 & 118.50 & 119.30 \\
\hline A4 & $\mathrm{C} 1-\mathrm{C} 2-\mathrm{C} 3$ & 119.31 & 119.30 & 119.48 & 119.40 & 119.38 \\
\hline A5 & $\mathrm{C} 1-\mathrm{C} 2-\mathrm{H} 9$ & 121.07 & 121.10 & 120.94 & 120.95 & 120.30 \\
\hline A6 & C3-C2-H9 & 119.61 & 119.59 & 119.57 & 119.64 & 120.30 \\
\hline A7 & $\mathrm{C} 2-\mathrm{C} 3-\mathrm{C} 4$ & 119.84 & 118.86 & 119.35 & 119.30 & 119.80 \\
\hline A8 & $\mathrm{C} 2-\mathrm{C} 3-\mathrm{C} 10$ & 124.04 & 125.66 & 124.77 & 124.94 & 123.90 \\
\hline A9 & C4-C3-C10 & 116.10 & 115.47 & 115.87 & 115.75 & 116.30 \\
\hline A10 & $\mathrm{C} 3-\mathrm{C} 4-\mathrm{C} 5$ & 119.55 & 120.78 & 119.80 & 119.98 & 118.79 \\
\hline A11 & C3-C4-N19 & 123.43 & 124.38 & 123.71 & 123.95 & 123.48 \\
\hline A12 & C5-C4-N19 & 117.01 & 114.83 & 116.48 & 116.05 & 117.72 \\
\hline A13 & C4-C5-C6 & 119.76 & 119.17 & 119.70 & 119.58 & 120.04 \\
\hline A14 & $\mathrm{C} 4-\mathrm{C} 5-\mathrm{O} 20$ & 119.20 & 116.53 & 118.60 & 118.19 & 121.06 \\
\hline A15 & C6-C5-O20 & 121.02 & 124.29 & 121.69 & 122.22 & 118.90 \\
\hline A16 & C1-C6-C5 & 120.13 & 119.59 & 119.69 & 119.87 & 120.50 \\
\hline A17 & C1-C6-H11 & 120.70 & 121.14 & 120.89 & 120.90 & 119.80 \\
\hline A18 & C5-C6-H11 & 119.15 & 119.26 & 119.13 & 119.22 & 119.80 \\
\hline A19 & C3-C10-H7 & 119.44 & 119.33 & 119.43 & 119.47 & 120.00 \\
\hline $\mathrm{A} 20$ & C3-C10-C13 & 119.76 & 119.85 & 119.87 & 119.85 & 119.93 \\
\hline A21 & H7-C10-C13 & 120.78 & 120.81 & 120.68 & 120.67 & 120.00 \\
\hline A22 & C13-C12-C15 & 119.65 & 120.67 & 120.32 & 120.41 & 120.53 \\
\hline A23 & C13-C12-N19 & 121.70 & 120.91 & 121.47 & 121.40 & 121.96 \\
\hline A24 & C15-C12-N19 & 118.64 & 118.40 & 118.19 & 118.18 & 117.50 \\
\hline A25 & $\mathrm{C} 10-\mathrm{C} 13-\mathrm{C} 12$ & 119.55 & 120.34 & 119.99 & 120.04 & 120.10 \\
\hline A26 & C10-C13-H14 & 121.07 & 120.77 & 120.74 & 120.69 & 120.00 \\
\hline A27 & C12-C13-H14 & 119.36 & 118.88 & 119.25 & 119.25 & 120.00 \\
\hline A28 & C12-C15-H16 & 110.60 & 111.18 & 110.98 & 110.98 & 109.50 \\
\hline A29 & C12-C15-H17 & 110.60 & 111.18 & 110.98 & 110.98 & 109.50 \\
\hline A30 & C12-C15-H18 & 109.98 & 109.84 & 109.93 & 109.95 & 109.50 \\
\hline A31 & H16-C15-H17 & 107.58 & 106.89 & 107.23 & 107.22 & 109.50 \\
\hline A32 & H16-C15-H18 & 109.00 & 108.81 & 108.81 & 108.81 & 109.50 \\
\hline A33 & H17-C15-H18 & 109.00 & 108.81 & 108.81 & 108.80 & 109.50 \\
\hline A34 & C4-N19-C12 & 119.42 & 119.03 & 119.06 & 118.98 & 118.15 \\
\hline A35 & C5-O20-H21 & 107.98 & 102.25 & 105.40 & 104.57 & 113.00 \\
\hline
\end{tabular}


The O-H bond distance have been calculated at the 6$311 \mathrm{G}^{* *}$ level to be 0.964(HF), 1.001(B3LYP), 0.972(BLYP) and $0.975 \AA$ (B3PW91). In previous work, this O-H bond is calculated as 0.948(HF), 0.974(B3LYP) and 0.860(B3PW91) with $6-31 \mathrm{G}^{* *}$ level for 5,7-dichloro-8-hydroxyquinaldine ${ }^{13}$. Also, this bond length was calculated as $0.949(\mathrm{HF})$ and 0.980(B3LYP) with 6-31G** level for 7-bromo-5-chloro-8hydroxyquinoline ${ }^{24}$.

The $\mathrm{C} 12-\mathrm{C} 15$ bond distance have been calculated at the 6-311G** level to be 1.505(HF), 1.482(B3LYP), 1.506(BLYP) and $1.500 \AA$ (B3PW91). Previous results are $1.506(\mathrm{HF})$, 1.508(B3LYP), 1.503(B3PW91) for 5,7-dichloro-8-hydroxyquinaldine ${ }^{13}$. This bond length was calculated as $1.51(\mathrm{HF}$, B3LYP) for 4-amino-2-methylquinoline ${ }^{16}, 1.54(\mathrm{~B} 3 \mathrm{LYP})^{17}$ and 1.5063(HF), 1.5085(B3LYP) for 2-methylquinoline ${ }^{25}$ and $1.507 \AA$ (HF, B3LYP) for lepidine ${ }^{22}$. This bond is quite longer than other experimental and theoretical calculations. The $\mathrm{C} 12-$ $\mathrm{C} 15$ bond distance is longer than other bond is due to the steric repulsion between $\mathrm{C} 12$ atom and methyl group.

Table-1 showed that the $\mathrm{C} 5-\mathrm{O} 20$ bond distance have been calculated at the 6-311G** level to be 1.337(HF), 1.327(B3LYP), 1.348(BLYP) and $1.342 \AA$ (B3PW91). This C5-O20 bond distance was calculated as $1.350(\mathrm{~B} 3 \mathrm{LYP})^{11}, 1.333(\mathrm{HF}), 1.348$ (B3LYP) and 1.342 (B3PW91) ${ }^{13}, 1.349$ (BLYP) ${ }^{26}$ and 1.328(HF), 1.342 (B3LYP) ${ }^{24}$. The experimental C5-O20 bond distance is longer than the theoretical calculations.

The calculated bond angles are close to each other except for the CCC bond angle at the point of methyl group substitution. With the electron donating substituent on the benzene ring, the symmetry of the ring is distorted, yielding ring angles smaller than $120^{\circ}$ at the point of substitution and slightly larger than $120^{\circ}$ at the ortho and meta positions ${ }^{27}$. Similar trend is not observed in 2-methyl-8-quinolinol. The C13-C12-N19 angle at the point of methyl group substitution is around $121.37^{\circ}$ while at meta $\mathrm{C} 10-\mathrm{C} 13-\mathrm{C} 12$ and para, $\mathrm{C} 3-\mathrm{C} 10-\mathrm{C} 13$ positions the angles are found to be around 119.98 and $119.83^{\circ}$, respectively. The $\mathrm{C} 13-\mathrm{C} 12-\mathrm{N} 19$ angle was calculated as 123.28(HF) and 123.33(B3LYP) with 6-31G** level ${ }^{16}$, 120.47(B3LYP) with $6-311+\mathrm{G}^{* *}$ level $^{17}, 121.9(\mathrm{HF})$, 122.1(B3LYP) and 122.1(B3PW91) with 6-31G* level ${ }^{13}$. Introduction of methyl group leads to significant perturbations in the substituted of pyridine ring, although the geometry of the benzene ring is seen to be relatively unperturbed.

The correlations graphics between the experimental and calculated bond lengths obtained by the several methods is shown in Fig. 3. According to our calculations, DFT/BLYP method correlates well for the bond length compared with the other HF, DFT/B3LYP and DFT/B3PW91 methods for 2methyl-8-quinolinol molecule. Also, the HF method correlates well for the bond angle compared with other DFT/B3LYP, DFT/BLYP and DFT/B3PW91 methods for 2-methyl-8quinolinol molecule (Fig. 4).

Vibrational assignments: The observed and theoretical FTIR and FT-Raman spectra of 2-methyl-8-quinolinol are given in Fig. 5. The observed and calculated frequencies using ab initio HF/6-311G**, B3LYP/6-311G**, BLYP/6-311G** and B3PW91/6-311G** along with their relative intensities, probable assignments in Table-2.
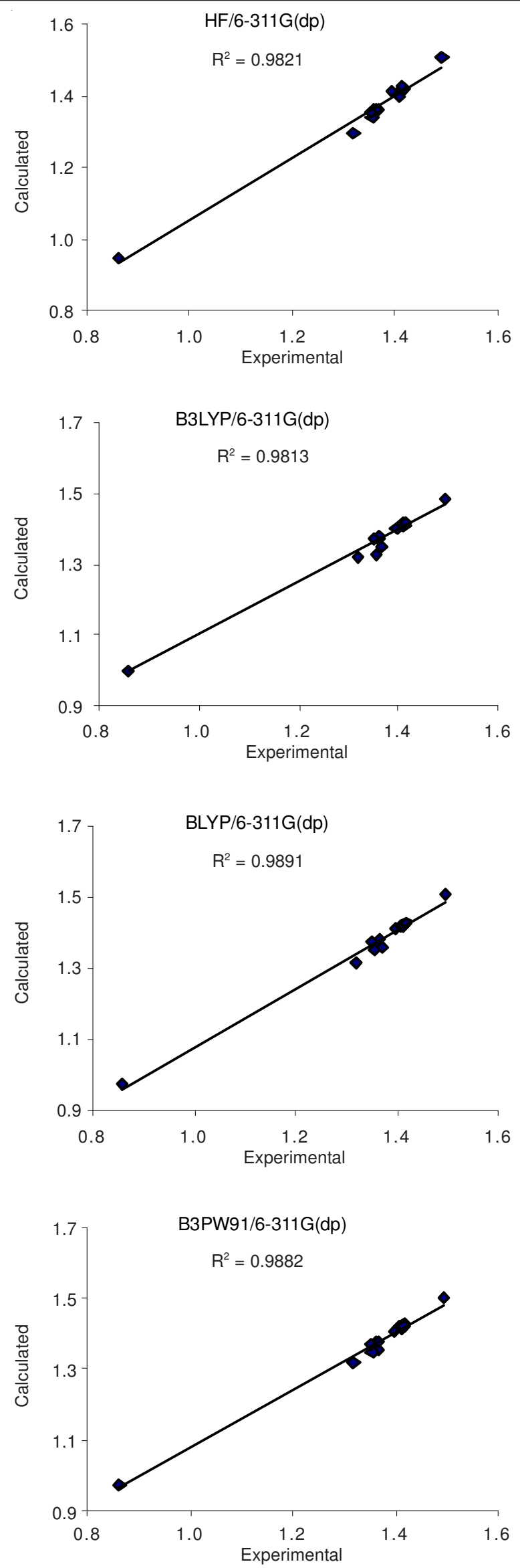

Fig. 3. Correlations graphics of bond lengths for 2-methyl-8-quinolinol molecule 

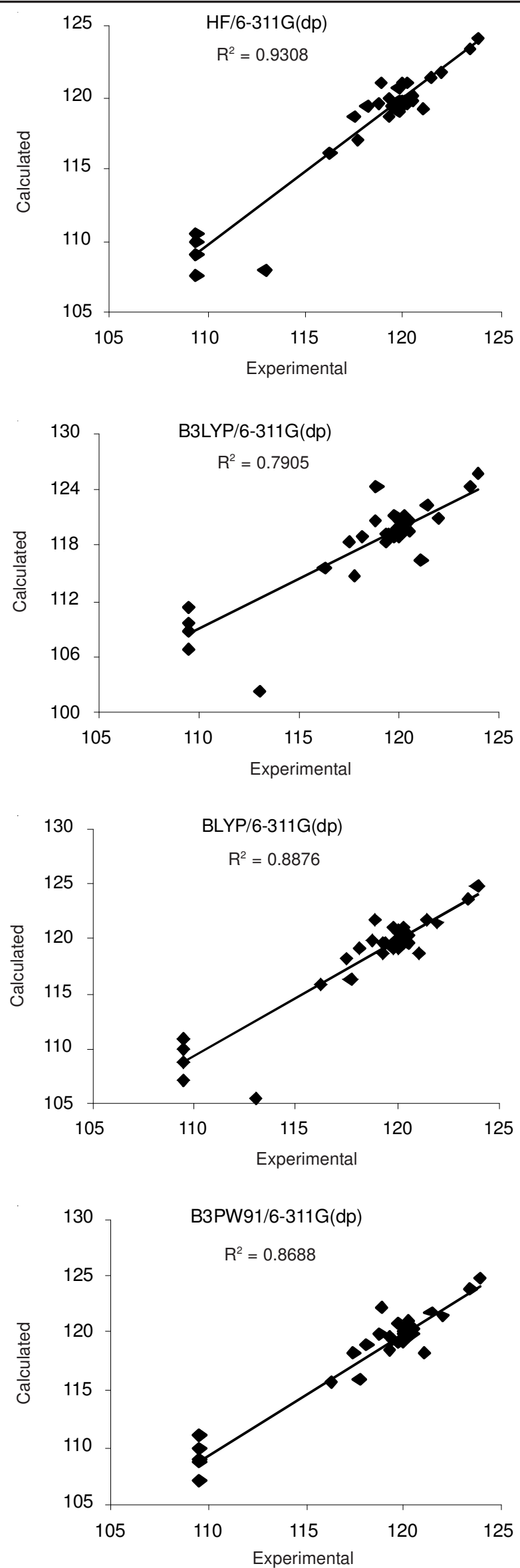

Fig. 4. Correlations graphics of bond angle for 2-methyl-8-quinolinol molecule
OH vibrations: The $\mathrm{O}-\mathrm{H}$ stretching vibrations are sensitive to hydrogen bonding. The non-hydrogen bonded or free hydroxyl group absorbed strongly and sharp in 3670-3580 $\mathrm{cm}^{-1}$. But in Raman spectra the O-H band is generally week. For solids, liquids and concentrated solutions a broad band of less intensity is normal observed ${ }^{28-30}$. Inter-molecular hydrogen bonding if present would reduce the $\mathrm{O}-\mathrm{H}$ stretching band to $3550-3200 \mathrm{~cm}^{-1}$ region ${ }^{31}$. In the present study, medium broad is observed at $3272 \mathrm{~cm}^{-1}$ to $\mathrm{O}-\mathrm{H}$ stretching vibration, which show that 2-methyl-8-quinolinol molecule possesses an intermolecular hydrogen bond in solid state. This band is not observed in the Raman spectra. The theoretical scaled O-H stretching frequencies are (3713)HF, (3150)B3LYP, (3655)BLYP and (3489)B3PW91 with 6-311G** set. The $\mathrm{O}-\mathrm{H}$ in-plane bending vibration is observed in the region 1440$1260 \mathrm{~cm}^{-1} 32$. The $\mathrm{O}-\mathrm{H}$ in-plane bending vibration is observed at 1381 and $1382 \mathrm{~cm}^{-1}$ to be medium strong band in infrared and wery strong in Raman spectra, respectively. The $1381 \mathrm{~cm}^{-1}$ band is calculated to be (1393)HF, (1356)B3LYP, (1435)BLYP and (1394)B3PW91 with 6-311G** set. The out-of-plane bending of $\mathrm{O}-\mathrm{H}$ is observed at $609 \mathrm{~cm}^{-1}$ in the infrared spectra to be medium strong. The out-of-plane bending band is calculated at (588)HF, (643)B3LYP, (631)BLYP and (637)B3PW91 with $6-311 \mathrm{G}^{* *}$. The $\mathrm{C}-(\mathrm{OH})$ stretching band is observed at $1244 \mathrm{~cm}^{-1}$ (strong) and at $1247 \mathrm{~cm}^{-1}$ (weak) in infrared and Raman spectra, respectively of 2-methyl-8-quinolinol molecule. The 321 and $225 \mathrm{~cm}^{-1}$ in Raman bands can be attributed to $\mathrm{C}-(\mathrm{OH})$ in-plane-bending vibration and $\mathrm{C}-(\mathrm{OH})$ out-of-plane bending vibration, respectively ${ }^{10,13,24}$.

C-H vibrations: The aromatic $\mathrm{C}-\mathrm{H}$ stretching vibrations are normally observed between 3050 and $3000 \mathrm{~cm}^{-1}$. The $\mathrm{C}-\mathrm{H}$ stretching of 2-methyl-8-quinolinol molecule gives bands at 3049,3027 and $3002 \mathrm{~cm}^{-1}$ in infrared spectra to be weak and at 3058 (strong), 3028, 3019 and $3004 \mathrm{~cm}^{-1}$ in Raman spectra to be weak. The aromatic $\mathrm{C}-\mathrm{H}$ stretching vibrations are generally highly pure modes. The $\mathrm{C}-\mathrm{H}$ in-plane bending modes are observed in region $1200-1000 \mathrm{~cm}^{-1}$. These modes are observed at 1160, 1140, 1094, 1051 and $1028 \mathrm{~cm}^{-1}$ in the infrared spectra and the corresponding frequencies are obtained in the Raman at 1142 and $1096 \mathrm{~cm}^{-1}$ in Table-2. The C-H outof-plane bending modes are observed in the region 1100-760 $\mathrm{cm}^{-1}$. The aromatic C-H out-of plane bending vibrations of 2-methyl-8-quinolinol are assigned to the bands observed at $970,959,887,830$ and $759 \mathrm{~cm}^{-1}$ in the infrared spectrum ${ }^{10}$. These bands not observed in Raman spectra of 2-methyl-8quinolinol molecule. $\mathrm{C}-\mathrm{H}$ vibrational frequencies calculated are given in Table-2.

Methyl group vibrations: There are nine basic methyl group vibrations. These are $\mathrm{v}_{\mathrm{s}} \mathrm{CH}_{3}$ symmetric stretch, two $v_{\mathrm{a}} \mathrm{CH}_{3}$ asymmetric stretch, two $\mathrm{v}_{\mathrm{a}} \mathrm{CH}_{3}$ asymmetric bending, $v_{\mathrm{s}} \mathrm{CH}_{3}$ symmetric bending $\mathrm{CH}_{3}$ rocking, $\mathrm{CH}_{3}$ wagging and $\mathrm{CH}_{3}$ torsion. The $\mathrm{v}_{\mathrm{s}} \mathrm{CH}_{3}$ frequency is not observed in the infrared but asymmetric deformation modes $\mathrm{v}_{\mathrm{a}} \mathrm{CH}_{3}$ are assigned at 2918 and $2954 \mathrm{~cm}^{-1}$ under a" and a' species of 2-methyl-8-quinolinol molecule, respectively. The $\mathrm{v}_{\mathrm{a}} \mathrm{CH}_{3}$ asymmetric bending deformation modes are obtained at 1426 and $1469 \mathrm{~cm}^{-1}$ a' species. The symmetrical bending methyl deformational mode $v_{\mathrm{a}} \mathrm{CH}_{3}$ is not observed. The methyl deformational modes 
TABLE-2

OBSERVED FTIR, FT-RAMAN AND CALCULATED FREQUENCIES USING HF/6-311G**, B3LYP/6-311G**, BLYP/6-311G** AND B3PW91/6-311G** WITH SCALED FREQUENCIES, THEIR INTENSITIES AND PROBABLE ASSIGNMENTS OF 2M8Q

\begin{tabular}{|c|c|c|c|c|c|c|c|c|c|c|c|c|c|c|c|}
\hline \multirow{2}{*}{ Spc. } & \multicolumn{2}{|c|}{$\begin{array}{c}\text { Ob. wavenumber } \\
\left(\mathrm{cm}^{-1}\right)\end{array}$} & \multicolumn{3}{|c|}{ Cal. HF/6-311G** } & \multicolumn{3}{|c|}{ Cal. B3LYP/6-311G** } & \multicolumn{3}{|c|}{ Cal. BLYP/6-311G** } & \multicolumn{3}{|c|}{ Cal. B3PW91/6-311G** } & \multirow{2}{*}{$\begin{array}{c}\text { Probable } \\
\text { assignment }\end{array}$} \\
\hline & FTIR & FTRa & $\begin{array}{l}\text { Scaled }^{\mathrm{a}} \\
\left(\mathrm{cm}^{-1}\right)\end{array}$ & Ir. int. & Ra. act. & $\begin{array}{l}\text { Scaled }^{\mathrm{b}} \\
\left(\mathrm{cm}^{-1}\right)\end{array}$ & Ir. int. & Ra. act. & $\begin{array}{l}\text { Scaled }^{\mathrm{c}} \\
\left(\mathrm{cm}^{-1}\right)\end{array}$ & Ir. int. & Ra. act. & $\begin{array}{c}\text { Scaled }^{\mathrm{d}} \\
\left(\mathrm{cm}^{-1}\right)\end{array}$ & Ir. int. & Ra. act. & \\
\hline $\mathrm{A}^{\prime \prime}$ & - & $101 \mathrm{~s}$ & 80 & 0.34 & 0.07 & 59 & 0.57 & 0.31 & 65 & 0.33 & 0.16 & 62 & 0.38 & 0.20 & $\mathrm{t}\left(\mathrm{CH}_{3}\right)$ \\
\hline $\mathrm{A}^{\prime \prime}$ & - & - & 107 & 0.32 & 0.75 & 103 & 0.54 & 1.65 & 108 & 0.29 & 1.80 & 103 & 0.34 & 1.75 & $\mathrm{t}$ ring \\
\hline $\mathrm{A}^{\prime \prime}$ & - & - & 170 & 2.88 & 0.75 & 161 & 2.99 & 0.08 & 172 & 2.67 & 0.10 & 165 & 2.91 & 0.08 & Butterfly \\
\hline $\mathrm{A}^{\prime}$ & - & - & 218 & 0.14 & 026 & 214 & 0.86 & 1.53 & 224 & 0.46 & 0.55 & 214 & 0.57 & 0.54 & $\delta$ ring \\
\hline $\mathrm{A}^{\prime \prime}$ & - & $225 \mathrm{w}$ & 222 & 0.64 & 1.79 & 214 & 0.75 & 0.62 & 225 & 0.69 & 1.55 & 216 & 0.90 & 1.56 & $\begin{array}{l}\gamma\left(\mathrm{C}-\mathrm{H}_{3}\right)+ \\
\gamma(\mathrm{C}-\mathrm{OH})\end{array}$ \\
\hline $\mathrm{A}^{\prime \prime}$ & - & & 317 & 0.02 & 1.05 & 302 & 0.02 & 0.33 & 321 & 0.01 & 0.51 & 308 & 0.02 & 0.52 & Fluctuation \\
\hline $\mathrm{A}^{\prime}$ & - & $321 w$ & 356 & 8.30 & 1.36 & 353 & 14.64 & 1.91 & 366 & 10.10 & 1.85 & 352 & 11.28 & 1.71 & $\begin{array}{c}\delta(\mathrm{C}-\mathrm{OH})+ \\
\delta\left(\mathrm{C}-\mathrm{H}_{3}\right)\end{array}$ \\
\hline $\mathrm{A}^{\prime \prime}$ & $421 \mathrm{~ms}$ & $423 \mathrm{w}$ & 425 & 5.61 & 7.97 & 407 & 2.33 & 1.87 & 434 & 2.38 & 2.17 & 415 & 2.48 & 2.05 & $\gamma \mathrm{CCC}$ \\
\hline $\mathrm{A}^{\prime}$ & $438 \mathrm{~ms}$ & $441 \mathrm{~m}$ & 429 & 9.57 & 2.86 & 419 & 5.44 & 8.98 & 440 & 4.94 & 9.18 & 424 & 5.13 & 9.00 & $v$ ring \\
\hline $\mathrm{A}^{\prime}$ & $495 \mathrm{~ms}$ & $497 \mathrm{w}$ & 478 & 3.22 & 4.94 & 476 & 2.29 & 7.54 & 504 & 2.96 & 6.31 & 483 & 2.91 & 6.67 & $\delta \mathrm{CNC}$ \\
\hline $\mathrm{A}^{\prime \prime}$ & $509 \mathrm{~ms}$ & & 500 & 56.77 & 1.39 & 483 & 2.44 & 0.42 & 519 & 0.67 & 0.24 & 497 & 1.23 & 0.22 & $\gamma \mathrm{CCC}$ \\
\hline $\mathrm{A}^{\prime}$ & $540 \mathrm{~s}$ & $543 \mathrm{w}$ & 532 & 57.39 & 0.65 & 532 & 3.48 & 6.34 & 555 & 3.55 & 5.59 & 532 & 3.74 & 5.52 & $\delta \mathrm{CCN}$ \\
\hline $\mathrm{A}^{\prime}$ & $572 w$ & & 538 & 4.44 & 4.55 & 544 & 0.59 & 9.56 & 566 & 0.47 & 9.83 & 545 & 0.65 & 9.49 & $\delta \mathrm{CNC}$ \\
\hline $\mathrm{A}^{\prime \prime}$ & - & $558 \mathrm{~m}$ & 544 & 1.04 & 7.25 & 561 & 0.69 & 1.17 & 593 & 2.37 & 0.90 & 570 & 0.65 & 9.40 & $\gamma \mathrm{CCC}$ \\
\hline $\mathrm{A}^{\prime \prime}$ & 609 br & & 588 & 0.51 & 0.72 & 643 & 3.48 & 0.06 & 631 & 92.57 & 1.82 & 637 & 76.85 & 1.03 & $\gamma \mathrm{OH}$ \\
\hline $\mathrm{A}^{\prime \prime}$ & $695 \mathrm{~s}$ & $697 \mathrm{~m}$ & 672 & 0.71 & 0.66 & 677 & 0.60 & 5.47 & 682 & 2.01 & 0.51 & 660 & 16.22 & 1.00 & $\gamma \mathrm{CCN}$ \\
\hline $\mathrm{A}^{\prime}$ & 722 vs & $728 \mathrm{~ms}$ & 676 & 0.78 & 7.40 & 705 & 38.90 & 0.69 & 705 & 0.93 & 7.07 & 680 & 0.89 & 6.97 & $\delta \mathrm{CCC}$ \\
\hline $\mathrm{A}^{\prime}$ & $747 \mathrm{vs}$ & - & 712 & 23.91 & 13.99 & 710 & 12.81 & 23.29 & 737 & 16.92 & 19.31 & 712 & 16.01 & 20.67 & $\delta \mathrm{CCC}$ \\
\hline $\mathrm{A}^{\prime \prime}$ & $759 \mathrm{~ms}$ & - & 767 & 46.02 & 0.06 & 757 & 23.19 & 1.57 & 766 & 36.21 & 0.45 & 734 & 37.94 & 0.30 & $\gamma \mathrm{CH}$ \\
\hline $\mathrm{A}^{\prime \prime}$ & $795 \mathrm{~ms}$ & - & 805 & 3.70 & 0.80 & 764 & 79.81 & 0.75 & 807 & 3.31 & 0.53 & 776 & 3.50 & 0.42 & $\gamma \mathrm{CNC}$ \\
\hline $\mathrm{A}^{\prime \prime}$ & 830 vs & - & 845 & 54.27 & 0.11 & 786 & 24.40 & 0.49 & 848 & 43.44 & 0.28 & 814 & 44.58 & 0.19 & $\gamma \mathrm{CH}$ \\
\hline $\mathrm{A}^{\prime}$ & $867 \mathrm{~ms}$ & 869 w & 849 & 4.62 & 2.27 & 825 & 0.20 & 1.04 & 882 & 4.88 & 1.73 & 849 & 40.74 & 1.94 & $\delta \mathrm{CCC}$ \\
\hline $\mathrm{A}^{\prime \prime}$ & 887 w & - & 888 & 1.11 & 1.92 & 839 & 5.35 & 1.44 & 893 & 0.45 & 1.14 & 856 & 0.30 & 0.93 & $\gamma \mathrm{CH}$ \\
\hline $\mathrm{A}^{\prime}$ & 910w & $909 \mathrm{w}$ & 900 & 1.91 & 1.90 & 891 & 0.12 & 3.48 & 929 & 0.31 & 2.76 & 898 & 0.12 & 2.99 & $\delta \mathrm{CCC}$ \\
\hline $\mathrm{A}^{\prime \prime}$ & $959 \mathrm{w}$ & - & 989 & 0.63 & 0.82 & 902 & 0.25 & 0.25 & 976 & 0.29 & 0.27 & 938 & 0.28 & 0.24 & $\gamma \mathrm{CH}$ \\
\hline $\mathrm{A}^{\prime \prime}$ & $970 \mathrm{w}$ & - & 991 & 5.83 & 1.46 & 929 & 0.52 & 0.10 & 999 & 0.35 & 0.13 & 959 & 0.38 & 0.14 & $\gamma \mathrm{CH}$ \\
\hline $\mathrm{A}^{\prime}$ & $981 \mathrm{~m}$ & - & 1013 & 0.23 & 0.81 & 948 & 5.99 & 0.85 & 1016 & 7.66 & 0.88 & 975 & 7.52 & 0.90 & $\begin{array}{c}\text { Wagging } \\
\left.\mathrm{CH}_{3}\right)\end{array}$ \\
\hline $\mathrm{A}^{\prime \prime}$ & $1002 \mathrm{~ms}$ & - & 1020 & 3.26 & 8.29 & 972 & 7.16 & 0.22 & 1060 & 3.32 & 0.16 & 1012 & 4.36 & 0.14 & $\begin{array}{l}\text { Rocking } \\
\left(\mathrm{CH}_{3}\right)\end{array}$ \\
\hline $\mathrm{A}^{\prime}$ & $1028 \mathrm{~ms}$ & - & 1050 & 3.25 & 0.42 & 1014 & 3.40 & 11.01 & 1071 & 1.83 & 11.18 & 1034 & 2.25 & 11.17 & $\delta \mathrm{CH}$ \\
\hline $\mathrm{A}^{\prime}$ & $1051 \mathrm{~ms}$ & $1056 \mathrm{w}$ & 1080 & 0.22 & 3.19 & 1061 & 16.42 & 0.78 & 1116 & 21.73 & 0.95 & 1077 & 18.80 & 0.88 & $\delta \mathrm{CH}$ \\
\hline $\mathrm{A}^{\prime}$ & $1094 \mathrm{~ms}$ & $1096 \mathrm{vw}$ & 1086 & 29.46 & 2.81 & 1085 & 4.36 & 6.39 & 1164 & 0.81 & 5.38 & 1120 & 1084 & 5.48 & $\delta \mathrm{CH}$ \\
\hline $\mathrm{A}^{\prime}$ & $1140 \mathrm{~s}$ & $1142 \mathrm{w}$ & 1159 & 21.13 & 10.36 & 1114 & 7.54 & 2.87 & 1195 & 11.58 & 2.09 & 1147 & 11.47 & 2.37 & $\delta \mathrm{CH}$ \\
\hline $\mathrm{A}^{\prime}$ & 1160 vs & - & 1173 & 2.22 & 4.64 & 1172 & 7.05 & 0.77 & 1231 & 27.49 & 0.35 & 1192 & 28.99 & 0.21 & $\delta \mathrm{CH}$ \\
\hline $\mathrm{A}^{\prime}$ & $1183 \mathrm{~ms}$ & $1175 \mathrm{vw}$ & 1209 & 24.48 & 5.80 & 1207 & 10.73 & 1.59 & 1247 & 14.00 & 0.52 & 1210 & 5.12 & 0.75 & $v \mathrm{CC}$ \\
\hline $\mathrm{A}^{\prime}$ & $1215 \mathrm{~ms}$ & $1216 \mathrm{w}$ & 1255 & 155.58 & 4.96 & 1239 & 78.89 & 6.79 & 1291 & 147.46 & 24.07 & 1248 & 128.55 & 15.35 & $v \mathrm{CC}$ \\
\hline $\mathrm{A}^{\prime}$ & 1244 vs & $1247 \mathrm{w}$ & 1259 & 36.00 & 4.88 & 1270 & 11.66 & 15.77 & 1303 & 8.95 & 3.66 & 1265 & 10.85 & 8.08 & $v(\mathrm{C}-\mathrm{OH})$ \\
\hline $\mathrm{A}^{\prime}$ & $1325 \mathrm{~s}$ & - & 1322 & 75.06 & 22.41 & 1298 & 16.46 & 25.50 & 1359 & 61.92 & 1.74 & 1319 & 61.80 & 1.42 & $v \mathrm{CN}$ \\
\hline $\mathrm{A}^{\prime}$ & - & - & 1359 & 9.11 & 211.15 & 1319 & 45.45 & 7.37 & 1398 & 21.48 & 150.10 & 1347 & 6.56 & 25.11 & $\delta_{\mathrm{s}}\left(\mathrm{CH}_{3}\right)$ \\
\hline $\mathrm{A}^{\prime}$ & $1357 \mathrm{~ms}$ & $1352 \mathrm{w}$ & 1381 & 20.27 & 37.95 & 1355 & 41.13 & 44.48 & 1412 & 3.46 & 15.66 & 1365 & 30.30 & 88.51 & vCC \\
\hline $\mathrm{A}^{\prime}$ & $1381 \mathrm{~ms}$ & 1382 vs & 1393 & 12.33 & 1.74 & 1356 & 11.84 & 13.28 & 1435 & 23.98 & 27.07 & 1394 & 33.98 & 35.23 & $\delta \mathrm{OH}+\mathrm{vCC}$ \\
\hline $\mathrm{A}^{\prime}$ & $1426 \mathrm{~ms}$ & $1438 \mathrm{~s}$ & 1435 & 48.86 & 27.93 & 1375 & 105.24 & 36.12 & 1468 & 51.69 & 20.30 & 1411 & 61.47 & 6.30 & $\delta_{\mathrm{a}}\left(\mathrm{CH}_{3}\right)$ \\
\hline $\mathrm{A}^{\prime}$ & $1469 \mathrm{~s}$ & - & 1450 & 27.56 & 48.53 & 1382 & 27.78 & 18.92 & 1484 & 39.04 & 89.69 & 1422 & 8.61 & 12.63 & $\delta_{\mathrm{a}}\left(\mathrm{CH}_{3}\right)$ \\
\hline $\mathrm{A}^{\prime \prime}$ & - & - & 1455 & 7.02 & 11.81 & 1432 & 7.83 & 174.01 & 1488 & 7.59 & 13.19 & 1424 & 12.93 & 145.73 & $v C C$ \\
\hline $\mathrm{A}^{\prime}$ & $1506 \mathrm{~s}$ & $1507 \mathrm{vw}$ & 1492 & 69.82 & 8.83 & 1459 & 70.27 & 7.00 & 1516 & 65.96 & 4.07 & 1466 & 74.12 & 5.49 & $v C C$ \\
\hline $\mathrm{A}^{\prime}$ & $1570 \mathrm{~s}$ & $1571 \mathrm{~ms}$ & 1513 & 170.48 & 1.72 & 1485 & 136.06 & 4.69 & 1549 & 102.18 & 2.21 & 1499 & 116.28 & 2.40 & vCC \\
\hline $\mathrm{A}^{\prime}$ & $1599 \mathrm{~ms}$ & $1596 \mathrm{w}$ & 1616 & 23.19 & 43.65 & 1559 & 71.36 & 11.36 & 1616 & 45.76 & 25.71 & 1568 & 52.23 & 22.27 & $v \mathrm{CN}+v \mathrm{CC}$ \\
\hline $\mathrm{A}^{\prime}$ & $1624 \mathrm{w}$ & $1624 \mathrm{w}$ & 1642 & 94.40 & 6.47 & 1580 & 35.98 & 35.15 & 1648 & 41.04 & 20.31 & 1596 & 40.74 & 23.37 & $v \mathrm{CC}$ \\
\hline $\mathrm{A}^{\prime}$ & - & - & 1665 & 7.92 & 6.85 & 1611 & 7.54 & 9.20 & 1676 & 2.95 & 7.75 & 1624 & 3.18 & 8.36 & $v \mathrm{CC}$ \\
\hline $\mathrm{A}^{\prime}$ & - & - & 2878 & 27.36 & 221.18 & 2872 & 8.24 & 394.93 & 3026 & 22.16 & 300.61 & 2926 & 18.74 & 312.42 & $v_{s}\left(\mathrm{CH}_{3}\right)$ \\
\hline $\mathrm{A}^{\prime \prime}$ & $2918 \mathrm{w}$ & $2921 \mathrm{~ms}$ & 2924 & 25.83 & 105.72 & 2935 & 3.84 & 137.76 & 3073 & 17.24 & 122.60 & 2938 & 12.80 & 120.23 & $v_{\mathrm{a}}\left(\mathrm{CH}_{3}\right)$ \\
\hline $\mathrm{A}^{\prime}$ & $2954 \mathrm{w}$ & - & 2978 & 13.99 & 61.03 & 2983 & 2.70 & 69.37 & 3132 & 9.54 & 62.27 & 3035 & 7.46 & 62.28 & $\mathrm{v}_{\mathrm{a}}\left(\mathrm{CH}_{3}\right)$ \\
\hline $\mathrm{A}^{\prime}$ & $3002 \mathrm{w}$ & $3004 \mathrm{w}$ & 3018 & 3.78 & 21.63 & 2993 & 3.13 & 85.48 & 3163 & 5.16 & 49.55 & 3058 & 4.68 & 60.40 & $\mathrm{vCH}$ \\
\hline
\end{tabular}




\begin{tabular}{ccccccccccccccccc}
\hline $\mathrm{A}^{\prime}$ & - & $3019 \mathrm{w}$ & 3021 & 2.34 & 90.21 & 3001 & 1.04 & 61.52 & 3167 & 1.45 & 81.58 & 3062 & 1.50 & 69.95 & $\mathrm{vCH}$ \\
$\mathrm{A}^{\prime}$ & - & - & 3036 & 23.31 & 114.35 & 3012 & 6.06 & 193.68 & 3182 & 14.23 & 124.94 & 3076 & 11.14 & 138.18 & $v \mathrm{CH}$ \\
$\mathrm{A}^{\prime}$ & $3027 \mathrm{w}$ & $3028 \mathrm{w}$ & 3041 & 23.27 & 150.29 & 3015 & 9.64 & 161.44 & 3183 & 27.02 & 202.45 & 3077 & 22.60 & 181.70 & $\mathrm{vCH}$ \\
$\mathrm{A}^{\prime}$ & $3049 \mathrm{w}$ & $3058 \mathrm{~s}$ & 3050 & 13.43 & 235.89 & 3029 & 1.19 & 247.90 & 3196 & 10.15 & 252.38 & 3090 & 7.48 & 242.14 & $\mathrm{vCH}$ \\
$\mathrm{A}^{\prime}$ & $3272 \mathrm{br}$ & - & 3713 & 134.45 & 35.96 & 3150 & 178.01 & 61.88 & 3655 & 105.52 & 53.23 & 3489 & 116.52 & 53.95 & $v \mathrm{OH}$ \\
\hline
\end{tabular}

${ }^{\mathrm{a}}$ Scaling factor (s.f.): 0.9085 , ${ }^{\mathrm{b}}$ s.f.: 0.9669 , ${ }^{\mathrm{c}}$ s.f.: 0.9962 , ${ }^{\mathrm{d}}$ s.f.: 0.9631 , act.: activity, cal.: calculated, def.: deformation, int.: intensity, m.: medium, ob.: observed, spc.: species, s.: strong, $v$ :stretching, $\delta$ :in-plane bending, $\delta_{\mathrm{s}}$ : symmetric bending, $\delta_{\mathrm{a}}$ : asymmetric bending, $v_{\mathrm{a}}$ : asymmetric stretching, $v_{\mathrm{s}}$ : symmetric stretching $\gamma$ :out of plane, $\tau$ :torsion, w.: weak, $v .:$ very.

IR Observed

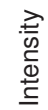

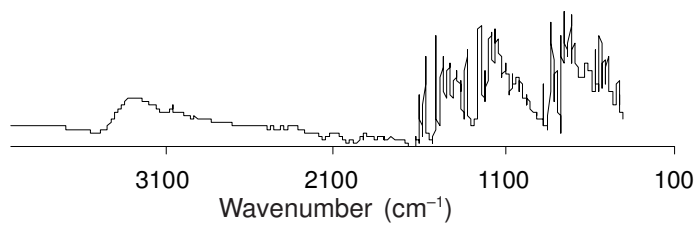

$\mathrm{HF} / 6-311 \mathrm{G}(\mathrm{dp})$
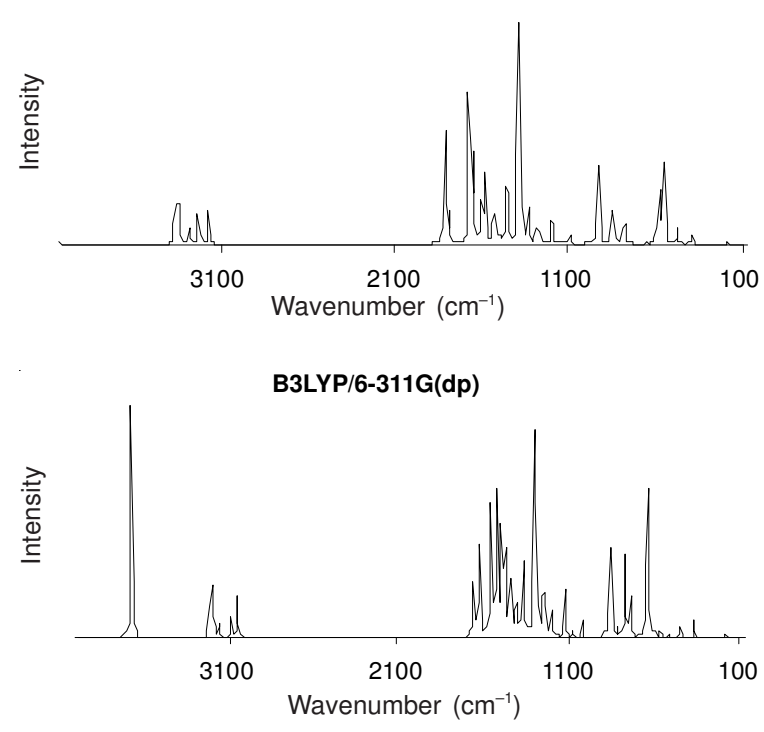

BLYP/6-311G(dp)

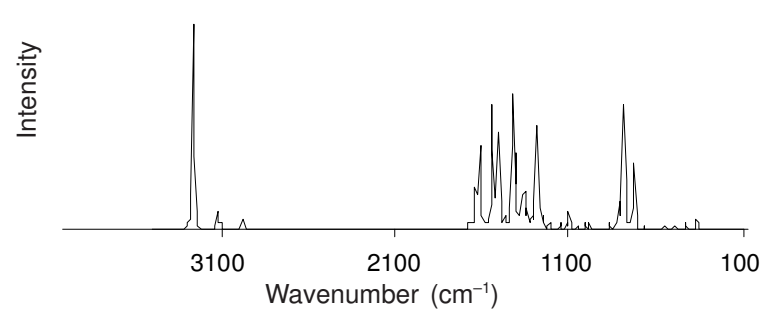

B3PW91/6-311G(dp)

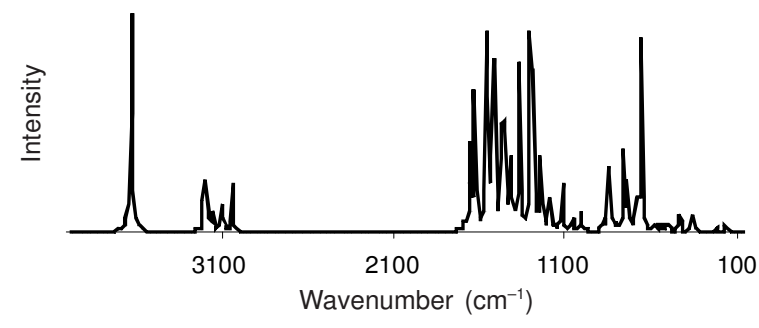

I: Column is infrared spectra

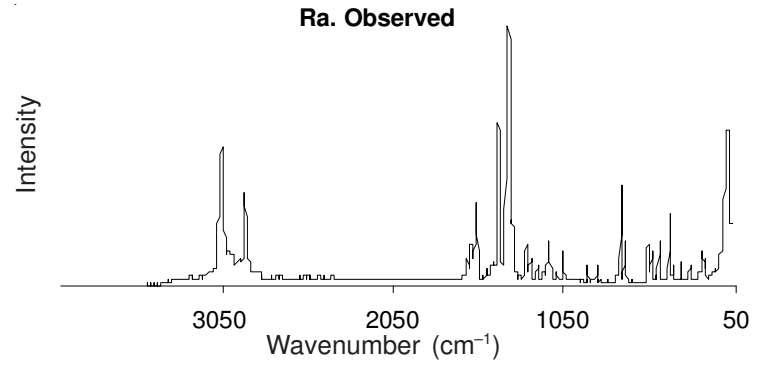

$\mathrm{HF} / 6-311 \mathrm{G}(\mathrm{dp})$
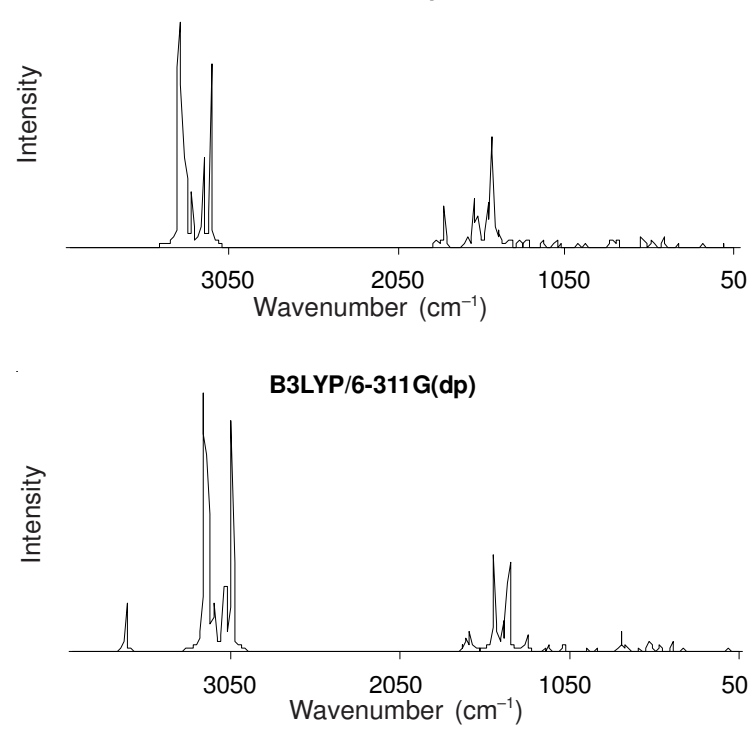

BLYP/6-311G(dp)
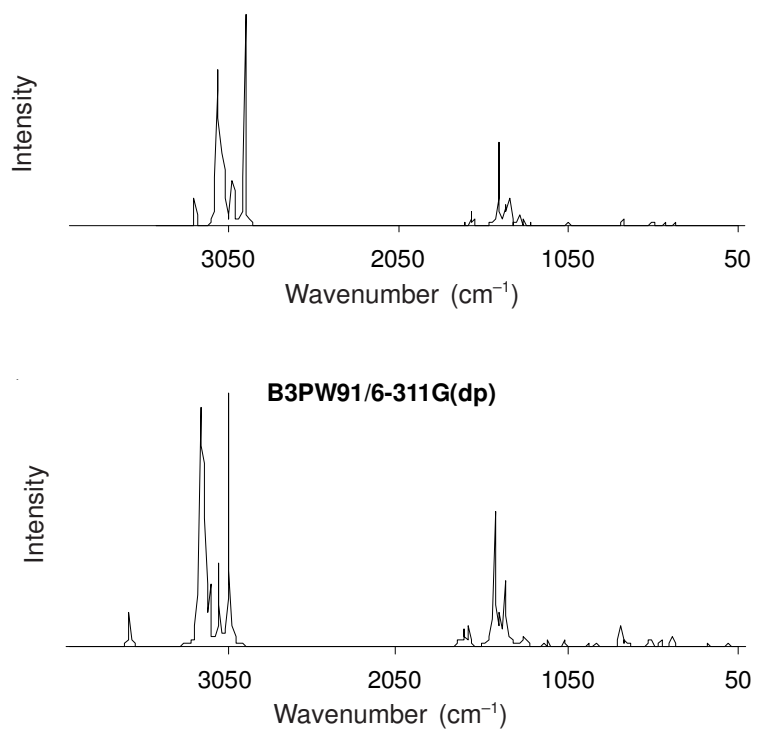

II: Column is Raman spectra

Fig. 5. Observed and calculated the spectra for 2-methyl-8-quinolinol molecule 
mainly coupled with the $\mathrm{C}-\mathrm{C}$ in-plane bending vibrations. The $\mathrm{CH}_{3}$ rocking and $\mathrm{CH}_{3}$ wagging modes of 2-methyl-8quinolinol are determined at 1002 and $981 \mathrm{~cm}^{-1}$ in infrared spectra. The $101 \mathrm{~cm}^{-1}$ strong band in Raman spectra is attributed $\mathrm{CH}_{3}$ torsion mode. These assignments are substantiated by the reported literature ${ }^{25}$.

Skeletal vibrations: The identification of vibrational modes in $1600-1300 \mathrm{~cm}^{-1}$ region is difficult task since the mixing of several bands are possible in this region. The $\mathrm{C}-\mathrm{C}$ stretching bands appeared in the infrared spectrum are assigned at $1624,1599,1570,1506,1381,1357,1215$ and $1185 \mathrm{~cm}^{-1}$ in the 2-methyl-8-quinolinol molecule under $\mathrm{C}_{\mathrm{s}}$ symmetry. The 1599 and $1325 \mathrm{~cm}^{-1}$ bands are assigned to the ring CN stretching vibrations. The corresponding $\mathrm{CC}$ and $\mathrm{CN}$ stretching modes observed in the Raman spectrum are given in Table-1. The bands occurring at 910, 867, 747, 722, 572, 540 and 495 $\mathrm{cm}^{-1}$ in the infrared are assigned to be in-plane bending modes. The 795, 695, 509 and $421 \mathrm{~cm}^{-1}$ bands can be attributed the out-of-plane bending ring vibrations of 2-methyl-8-quinolinol. The results are in good agreement with the literature values ${ }^{16,33-35}$. The vibrational assignments of the fundamental modes are also supported by Gaussview molecular visualization program ${ }^{20}$.

To make comparison with experimental, we present correlation graphics the frequencies for 2-methyl-8-quinolinol molecule in Fig. 6 based on the calculations. As can be seen from Fig. 6 experimental fundamentals are in better agreement with the scaled fundamentals and are found to have a good correlation for DFT/B3LYP than HF, DFT/BLYP and DFT/B3PW91 for 2-methyl-8-quinolinol molecule.
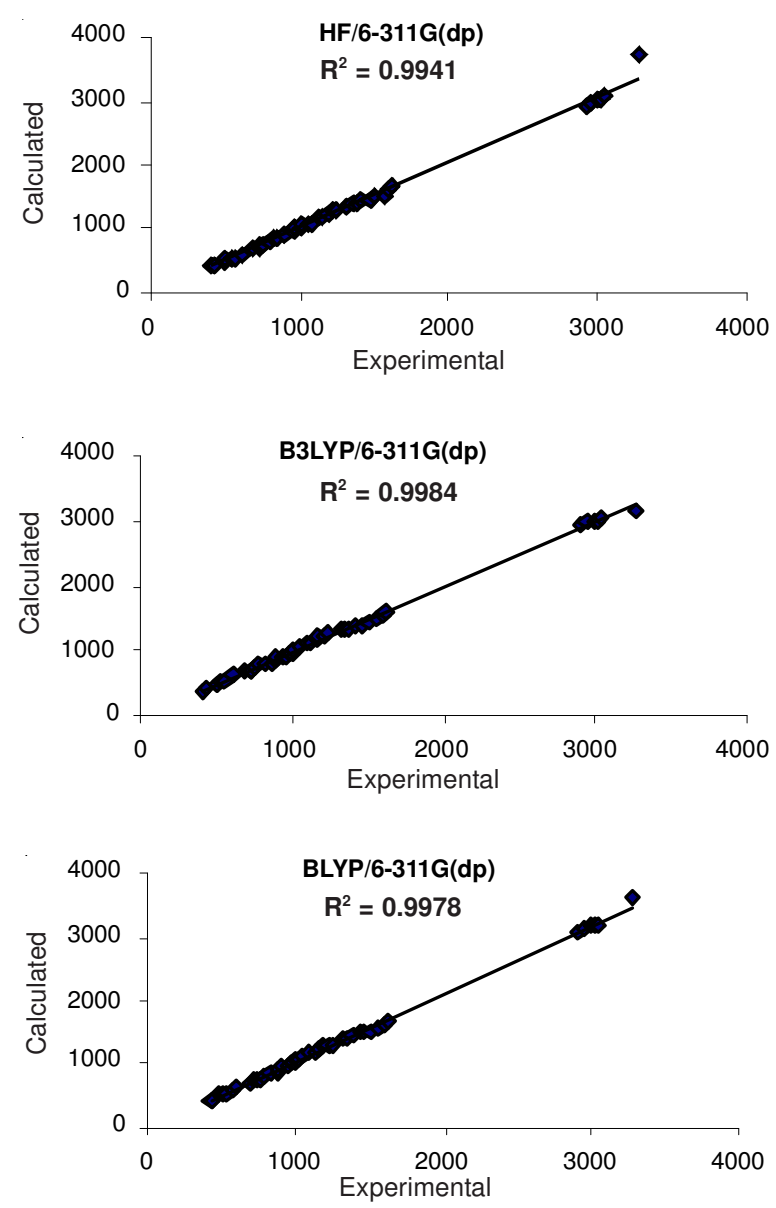

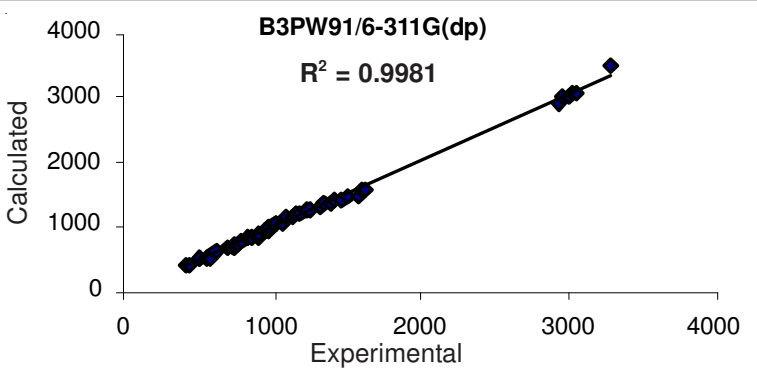

Fig. 6. Correlations graphics of frequencies for 2-methyl-8-quinolinol molecule

\section{Conclusion}

Infrared and Raman spectra have been obtained 2-methyl8-quinolinol molecule. The molecular structural parameters and vibrational frequencies of the fundamental modes of the 2-methyl-8-quinolinol molecule have been obtained from quantum mechanical $a b$ initio and DFT calculations. The geometry was optimized without any symmetry constraints using the HF and DFT(B3LYP, BLYP, B3PW91) method with 6-311G(dp) basis set. The theoretical results were compared with the experimental structure parameters and observed vibrational waven umbers. The bond length and bond angle parameters of 2-methyl-8-quinolinol molecule computed by DFT/BLYP and HF are in reasonable agreement with the experimental data, respectively. The infrared absorption and intensities computed by B3LYP method are agreement with experimental data. The results confirm the ability of the methodology applied for interpretation of the vibrational spectrum and geometric parameters of 2-methyl-8-quinolinol molecule in the solid state.

\section{ACKNOWLEDGEMENTS}

This work was supported by Kilis 7 Aralik University with BAP projects 2010/04 and 2010/02/08.

\section{REFERENCES}

1. R.E. Babry, In ed.: M.E. Wolf, Burger's Medicinal Chemistry, Part II, John Wiley, New York, pp. 41-81 (1979).

2. J.-H. Jeon, C.-H. Lee and H.-S. Lee, J. Korean Soc. Appl. Biol. Chem., 52, 202 (2009)

3. A.E. Martell and M. Calvin, Chemistry of Metal Chalete Compounds, Prentice Hall, Englewood Cliffs, Ch. 10 (1959).

4. (a) Z.J. Huang, X.G. Wang and J. Chang, Asian J. Chem., 22, 365 (2010); (b) B.S. Kumar, A. Abhilasha, W. Cyril and D. Sobhana, Asian J. Chem., 23, 889 (2011).

5. S. Mohan, N. Puviarasa and S. Bakkialakshmi, Spectrochim. Acta A, 55, 2911 (1999).

6. J.R. Rodrigues, de NG. Bominguez and B. Plasmodium, Exp. Parasitol, 115, 19 (2007).

7. F. Yousef, M.A. Mostafa, G. Shan and W.N. Seik, Acta Cryst., E64, 97 (2008).

8. S.L. Srivastava, M. Prasad and Rohitashava, Spectrochim. Acta, 40A, 681 (1984).

9. K. Arici, M. Yurdakul and S. Yurdakul, Spectrochim. Acta A, 61, 37 (2005).

10. V. Krishnakumar and R. Ramasany, Spectrochim. Acta A, 61, 673 (2005).

11. K. Bahgat and A. Ganie Ragheb, Central Eur. J. Chem., 5, 201 (2007).

12. K. Arici and H. Köksal, Asian J. Chem., 20, 5653 (2008).

13. K. Arici and H. Köksal, Asian J. Chem., 22, 2898 (2010).

14. R.G. Charles, H. Freiser, R. Friedel, L.E. Hilliard and D. William, Spectrochhim. Acta, 8, 1 (1965). 
15. R. Zvaans and C. Thomson, J. Mol. Struct.:Theochem., 362, 51 (1996).

16. V. Arjunan, I. Saravanan, P. Ravindran and S. Mohan, Spectrochhim. Acta, 74, 375 (2009)

17. V. Krishnakumar and R. John Xavier, Chem. Phys., 312, 227 (2005).

18. S.H. Vosko, L. Wilk and M. Nusair, Can. J. Phys., 58, 1200 (1980).

19. K.K. Irikura, D.R. Johnson III and N.R. Kacker, J. Phys. Chem. A, 109, 8435 (2005).

20. A. Frisch, A.B. Nielsen and A.J. Holder, Gaussview Users Manuel, Gaussian Inc., Pittsburg (2003).

21. Gaussian 09, Revision A.1, M.J. Frisch, G.W. Trucks, H.B. Schlegel, G.E. Scuseria, M.A. Robb, J.R. Cheeseman, G. Scalmani, V. Barone, B. Mennucci, G.A. Petersson, H. Nakatsuji, M. Caricato, X. Li, H.P. Hratchian, A.F. Izmaylov, J. Bloino, G. Zheng, J.L. Sonnenberg, M. Hada, M. Ehara, K. Toyota, R. Fukuda, J. Hasegawa, M. Ishida, T. Nakajima, Y. Honda, O. Kitao, H. Nakai, T. Vreven, J.A. Montgomery Jr., J.E. Peralta, F. Ogliaro, M. Bearpark, J.J. Heyd, E. Brothers, K.N. Kudin, V.N. Staroverov, R. Kobayashi, J. Normand, K. Raghavachari, A. Rendell, J.C. Burant, S.S. Iyengar, J. Tomasi, M. Cossi, N. Rega, N.J. Millam, M. Klene, J.E. Knox, J.B. Cross, V. Bakken, C. Adamo, J. Jaramillo, R. Gomperts, R.E. Stratmann, O. Yazyev, A.J. Austin, R. Cammi, C. Pomelli, J.W. Ochterski, R.L. Martin, K. Morokuma, V.G. Zakrzewski, G.A. Voth, P. Salvador, J.J. Dannenberg, S. Dapprich, A.D. Daniels, Ö. Farkas, J.B. Foresman, J.V. Ortiz, J. Cioslowski, D.J. Fox, Gaussian, Inc., Wallingford CT (2009).
22. M. Kurt and S. Yurdakul, J. Mol. Struct. (Theochem.), 730, 59 (2005).

23. M. Kurt and S. Yurdakul, J. Mol. Struct. (Theochem.), 804, 75 (2007).

24. V. Arjunan, S. Mohan, P. Ravindran and C.V. Mythill, Spectrochim. Acta A, 72, 783 (2009)

25. E. Aysen Özel, K. Serda and A. Sevim, Vibrational Spectrosc., 42, 325 (2006).

26. T. Dzimbowska, M. Szafran, E. Jagodzinska, I. Natkaniec, A. Pawlukoje, J.S. Kwiatkowski and J. Baran, Spectrochim. Acta A, 59, 2175 (2003).

27. Y. Wang, S. Saebar and C.U. Pittman Jr., J. Mol. Struct.: Theochem., 28, 91 (1993).

28. N.S. Sundra, Spectrochim. Acta, 42A, 1449 (1985).

29. E.T.G. Lutz and J.H. Van der Mass, Spectrochim. Acta, 42A, 755 (1986).

30. R.M. Silverstein, G.C. Bassler and T.C. Morrill, Spectrometric Identification of Organic Compounds, John Wiley \& Sons. Inc., New York (1981).

31. A. Ragheb, A. Shalabi and E. Sawi, J Serb. Chem. Soc., 52, 679 (1987).

32. D.N. Sathyanarayana, Vibrational Spectroscopy-Theory and Applications, New Age International (P) Limited Publishers, New Delhi edn. 2 (2004).

33. A. Altun, K. Gölcük and M. Kumru, J. Mol. Struct. (Theochem.), 637, 155 (2003)

34. N. Puviarasan, V. Arjunan and S. Mohan, Turk. J. Chem., 28, 53 (2004).

35. V. Arjunan, S. Mohan, S. Subramanian and B.T. Gowda, Spectrochim. Acta, 60A, 1141 (2004). 